\title{
BIOCHEMICAL CHARACTERIZATION OF VOLATILE SECONDARY METABOLITES PRODUCED BY Burkholderia gladioli pv. agaricicola
}

\section{ELSHAFIE H.S. ${ }^{1}$, BUFO S.A. ${ }^{2}$, RACIOPPI R. ${ }^{2}$ AND CAMELE I. ${ }^{1 *}$}

${ }^{1}$ School of Agricultural, Forestry, Food and Environmental Sciences, University of Basilicata, Via dell'Ateneo Lucano, 10, 85100 Potenza, Italy. 2Department of Science, University of Basilicata, Via dell'Ateneo Lucano, 10, 85100 Potenza, Italy.

${ }^{*}$ Corresponding Author: Email- ippolito.camele@unibas.it

Received: March 28, 2013; Accepted: April 25, 2013

\begin{abstract}
Numerous species in the genus Burkholderia have interesting properties for potential industrial applications including production of antibiotics, biosurfactants, bioplastics and degradation of environmental contaminants. The aims of this study were to determine the antifungal activity of volatile secondary metabolites produced by four strains of Burkholderia gladioli pv. agaricicola (Bga) against the two phytopathogenic fungi Fusarium oxysporum and Rhizoctonia solani and to characterize biochemically the volatile organic compounds (VOCs) produced by the most bioactive Bga strain ICMP11096 tested in this study using Gas Chromatography-Mass Spectrometry. The studied strains showed antifungal activity against the tested phytopathogenic fungi through production of volatile bioactive metabolites. The biochemical characterization of VOCs of Bga ICMP11096 has detected two bioactive volatile compounds. The first one was a liquid hydrocarbon cyclic terpene and was identified as cyclohexene 1-methyl-4-(1-methylethenyl) and commonly considered one of the more frequent $d$ - isomers of limonene. The second one was identified as 4-flavanone (4H-1-Benzopyran-4-one, 2, 3-dihydro-2-phenyl). The two produced VOCs could be the main responsible for the antifungal activity.
\end{abstract}

Keywords- Antifungal activity, Secondary metabolites, Organic volatile compounds, Gas Chromatography Mass Spectroscopy, d Limonene, 4 -Flavanone

Citation: Elshafie H.S., et al. (2013) Biochemical Characterization of Volatile Secondary Metabolites Produced by Burkholderia gladioli pv. agaricicola. International Journal of Drug Discovery, ISSN: 0975-4423 \& E-ISSN: 0975-914X, Volume 5, Issue 1, pp.-181-184.

Copyright: Copyright@2013 Elshafie H.S., et al. This is an open-access article distributed under the terms of the Creative Commons Attribution License, which permits unrestricted use, distribution and reproduction in any medium, provided the original author and source are credited.

\section{Introduction}

With the increase of the environmental concerns promising alternatives to synthetic pesticides come on scene, i.e. the production of new bioactive microbial substances and the application of biopesticides. Several bacteria species including some Pseudomonas and Burkholderia produce natural bioactive secondary metabolites such as Pyrrolnitrin and Pyoluteorin [1,2].

Recently, it was demonstrated that volatile organic compounds (VOCs) of bacteria such as terpenoids, phenylpropanoids and fatty acid derivatives can influence the growth of some fungi [3,4] and, in general, the inter- and intra-organismic communication signals [57]. Complex mixture of volatile lactones and terpenoids (including geosmin) produced by some marine Streptomyces species exhibited antibiotic properties [8]. Schöller, et al. [6] reported that different strains of Streptomyces species produced VOCs such as alkanes, alkenes, alcohols, esters, ketones, sulfur-containing compounds and terpenoids of which about $10 \%$ remain unidentified.

B. gladioli Zopf possesses a great potential as a plant pathogen antagonist [9]. B. gladioli pv. agaricicola Yabuuchi (Bga) is an important pathogen in the mushroom industry, since it causes soft rot of Agaricus bitorquis (Quélet) Saccardo and A. bisporus (Lange) Imbach [10]. Elshafie, et al. [11] have found that several strains of
Bga have antifungal activity against some serious phytopathogenic fungi by producing diffusible bioactive secondary metabolites in broth culture.

The aims of this study were to determine the antifungal activity of four strains of Bga against two phytopathogenic fungi and to identify and characterize biochemically VOCs produced by Bga strain ICMP11096 using Gas chromatography-Mass spectrometry (GC-MS).

\section{Materials and Methods \\ Studied Bacterial and Fungal Strains}

Bga strains were isolated from $A$. bitorquis and obtained from International Collection of Microorganisms from Plants (ICMP) (Landcare Research, Auckland, New Zealand). The tested strains were ICMP11096, ICMP11097, ICMP12220 and ICMP12322. Bacterial strains were maintained as lyophils at $4^{\circ} \mathrm{C}$ and subcultures were obtained on the medium King Agar B (KB) for $48 \mathrm{hrs}$. at $22^{\circ} \mathrm{C}$ [12]. The studied phytopathogenic fungi, Fusarium oxysporum Schlechtend: Fr (F.oxy) (isolate number 1357) and Rhizoctonia solani Kühn (R.sol) (isolate number 1312) were derived from tomato and potato respectively and maintained on potato dextrose agar (PDA) at $4^{\circ} \mathrm{C}$ at School of Agricultural, Forestry, Food and Environmental Sciences, University of Basilicata, Potenza, Italy. 


\section{Antifungal Activity of Volatile Secondary Metabolites}

The tested bacterial strains were grown on $14 \mathrm{ml} \mathrm{KB}$ medium in Petri dishes and incubated at $25^{\circ} \mathrm{C}$ for $24 \mathrm{hrs}$. The studied fungi were cultured on $14 \mathrm{ml} \mathrm{PDA}$ media in Petri dishes at $22^{\circ} \mathrm{C}$ for 96 hrs. The test was performed according to Wan, et al. [13] using a double-dish chamber containing target fungi-inoculated in one upward dish of PDA ( $9 \mathrm{~cm}$ diameter) and $100 \mu$ of bacterial suspension $\mathrm{Bga}$ on the downward dish of KB $(9 \mathrm{~cm}$ diameter). The chamber was sealed with Parafilm ${ }^{\mathrm{TM}}$ and incubated at $22^{\circ} \mathrm{C}$ in darkness for 4-5 days. Fungitoxicity of volatile metabolites was monitored and then expressed by measuring the diameter of mycelium growth $(\mathrm{mm})$. The experiment was carried out two times with three replicates. For biochemical characterization of VOCs with antifungal activity the most bioactive Bga strain was selected.

\section{Chemical Characterization of Volatile Metabolites of Bga IC- MP11096}

The fresh culture of studied bacteria $24 \mathrm{hrs}$. old was inoculated in glass tube of $10 \mathrm{ml}$ nutrient $\mathrm{KB}$ and incubated at $22^{\circ} \mathrm{C}$ for 5 days in darkness for collecting the volatile organic compounds. A qualitative analysis of VOCs has been carried out using Solid Phase Micro Extraction method (SPME) as following: an SPME fiber inserted inside the glass tube and then the tube was heated at $25^{\circ} \mathrm{C}$ for 20 min. The SPME analysis of headspace was applied as following: an SPME fiber coated with $100 \mu \mathrm{m}$ of non-grafted poly (dimethylsiloxane) phase (Supelco $57300-\mathrm{U}$, mounted on a Supelco 57330 support) was conditioned for $1 \mathrm{hr}$. at $250^{\circ} \mathrm{C}$ in a stream of helium. A single fiber was used for the complete study. A blank run was performed after each analysis in order to confirm that no residual compounds were polluting the fiber or the column. The fiber was later introduced into the injection port of a HP6890 plus gas chromatograph equipped with a Phenomenex Zebron ZB-5 MS capillary column ( $30 \mathrm{~m}$ x $0.25 \mathrm{~mm}$ ID x $0.25 \mu \mathrm{m}$ film thickness). A HP 5973 mass selective detector (mass range: 15-800 mAU; scan rate: 1.9 scan/s; EM voltage: 1435) was used as detector, helium at $0.8 \mathrm{ml}$ min was used as carrier gas. The injection port, equipped with a glass insert (internal diameter $0.75 \mathrm{~mm}$ ) was splitted at $250^{\circ} \mathrm{C}$. The desorption time of 1.0 min was used. Detector was maintained at $230^{\circ} \mathrm{C}$. Oven was maintained at $40^{\circ} \mathrm{C}$ for $2 \mathrm{~min}$, then the temperature was increased until $250^{\circ} \mathrm{C}\left(8^{\circ} \mathrm{C} / \mathrm{min}\right)$ for $10 \mathrm{~min}$. All the analyses were performed in triplicate. The chromatograms obtained from the total ion current were integrated without any correction for coelutions and the results were expressed as percent of the total area of peaks. All peaks were identified from their mass spectra by comparison with spectra in Wiley $6 \mathrm{~N}$ and NIST98 libraries.

\section{Bioactivity of Standards VOCs d Limonene and 4-Flavanone}

The antifungal activity of both 4-flavanone and $d$ limonene substances was screened against $F$. oxysporum and $R$. solani using a double-dish chamber [13] as following: plating $100 \mu$ of 4-flavanone $100 \mathrm{mg} / \mathrm{L}$ and/or $d$ limonene $100 \mu / / L$ in empty sterilized Petri dish and stated in one side of another PDA plate that was inoculated with fungal discs. The double-dish chamber was sealed with three layers of Parafilm and was incubated in darkness at $22^{\circ} \mathrm{C}$ for $4-5$ days. The experiment was carried out two times with three replicates. Fungitoxicity was expressed as a percentage of growth inhibition (PGI) in respect of control and calculated according to the formula of Zygadlo, et al. [14] as following [Eq-1]:

$$
\text { PGI }(\%)=100 \times(G C-G T) / G C
$$

Where: GC represents the average diameter in $\mathrm{mm}$ of fungal mycelium in control PDA.

GT represents the average diameter in $\mathrm{mm}$ of fungal mycelium on the treated PDA dish contain the standards of VOCs.

\section{Results and Discussion}

\section{Antifungal Activity of Volatile Secondary Metabolites}

Results of bioactivity assay demonstrated that all studied strains of Bga produced volatile secondary metabolites which were able to reduce the fungal mycelium growth of F.oxy and R.sol significantly after 5 days of incubation. In particular, ICMP11096 and ICMP12220 strains Bga showed the highest significant reduction of mycelium growth of F.oxy [Fig-1] whereas strains ICMP11096, ICMP11097 and ICMP12220 showed the highest significant reduction of mycelium growth of R.sol [Fig-2]. Strain ICMP11096 was selected for further biochemical analysis of VOCs.

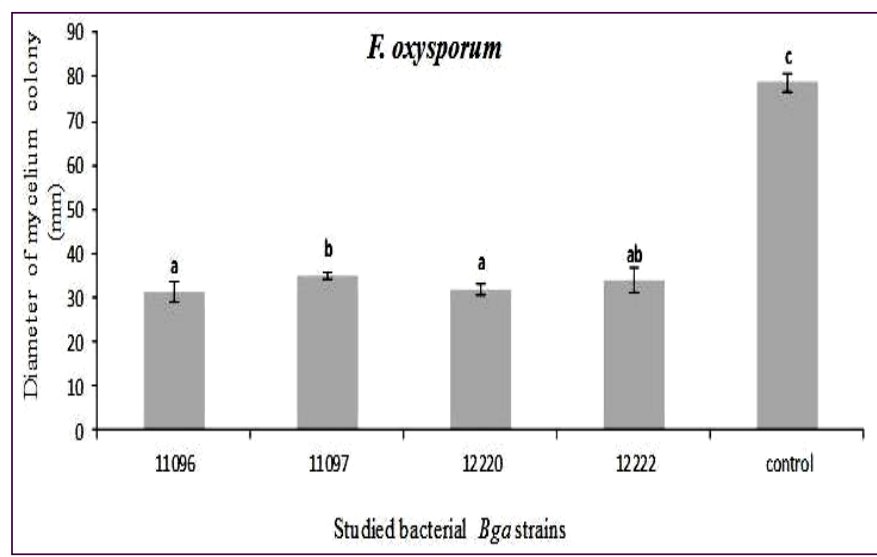

Fig. 1- Antifungal activity of volatile secondary metabolites of Burkholderia gladioli pv. agaricicola strains against Fusarium oxysporum.

*Bars with different letters indicate mean values significantly different at $P<0.05$ according to Duncan test; data are expressed as mean (SDS), $R=3$.

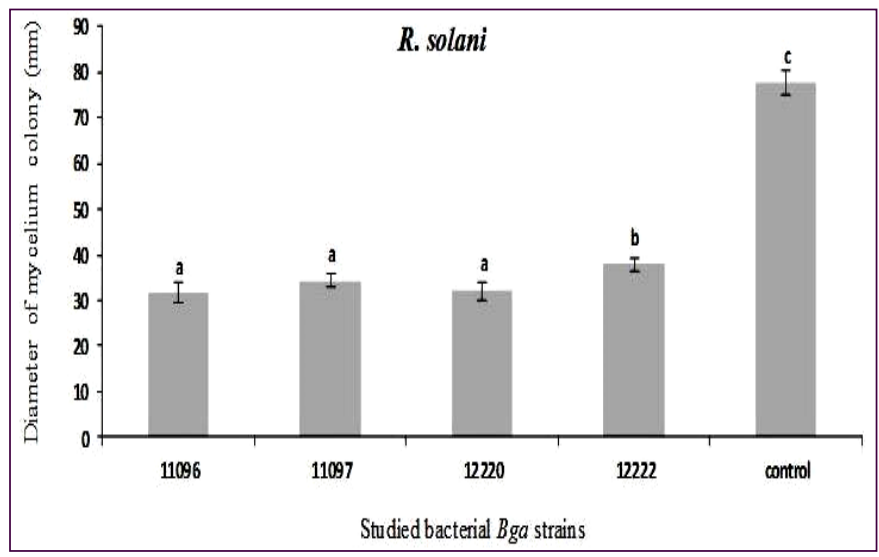

Fig. 2- Antifungal activity of volatile secondary metabolites of Burkholderia gladioli pv. agaricicola strains against Rhizoctonia solani.

${ }^{*}$ Bars with different letters indicate mean values significantly different at $P<0.05$ according to Duncan test, data are expressed as mean (SDS), $R=3$.

\section{Analysis of Volatile Substances by GC-MS}

Analysis of the VOCs emitted by ICMP11096 Bga strain using GC- 
MS evidenced the presence of two volatile compounds with molecular weight of $\mathrm{m} / \mathrm{z} 136$ and 224.1 at retention times of $8.9 \mathrm{~min}$ and $24.7 \mathrm{~min}$, respectively [Table-1].

The subsequent fragmentation of the two isolated volatile compounds using the Electrospray lonization and Ion Cyclotron Dissociation Mass Spectroscopy (ESI- CID MS/MS) showed that the first compound was a liquid hydrocarbon of cyclic terpene [Fig-3] whereas the second one was a 4-flavanone [Fig-4].

The first volatile compound was classified as liquid hydrocarbon of cyclic terpene and was expected to be a cyclohexene, 1-methyl-4(1-methylethenyl) and commonly considered one of the more frequent d-isomer of limonene. Similar results were obtained by Ayoola, et al. [15] who studied the antimicrobial activity of the volatile oil extracted from Citrus reticulata fruit peel and have revealed the presence of $d$ limonene which showed an antimicrobial properties against a wide range of microorganisms. On the other hand, Hoss- ain, et al. [16] have characterized the bioactivity of the extracted essential oils of Orthosiphon stamineus which has showed a remarkable antifungal effect against some phytopathogenic fungi due to the presence of caryophyllene, humulene, elemene, bourbonene, pinene, caryophyllene oxide, camphene and limonene.

Table 1- Chemical properties of identified VOCs from ICMP11096 Bga strain

\begin{tabular}{lcc}
\hline VOCs & 4-Flavanone \\
Molecular structure & 1-methyl-4-(1-methylethenyl)- & $4 \mathrm{H}-1$-Benzopyran-4-one, 2, 3- \\
& dihydro-2-phenyl \\
IUPAC ID & $\mathrm{Cychene}_{10} \mathrm{H}_{16}$ & $\mathrm{C}_{15} \mathrm{H}_{12} \mathrm{O}_{2}$ \\
Molecular Formula & $136.24 \mathrm{~g} / \mathrm{mol}$ & $224.1 \mathrm{~g} / \mathrm{mol}$ \\
Molar mass & $-74.35^{\circ} \mathrm{C}$ & $76^{\circ} \mathrm{C}$ \\
Melting point & $8.9 \mathrm{~min}$ & $24.7 \mathrm{~min}$ \\
Retention time & &
\end{tabular}

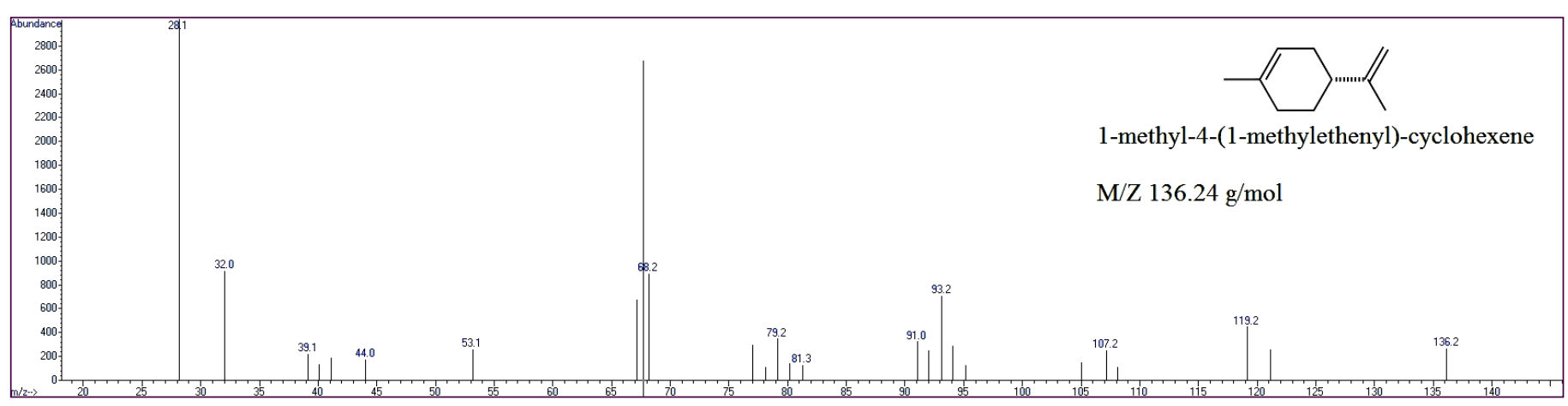

Fig. 3- Mass spectrum of d Limonene

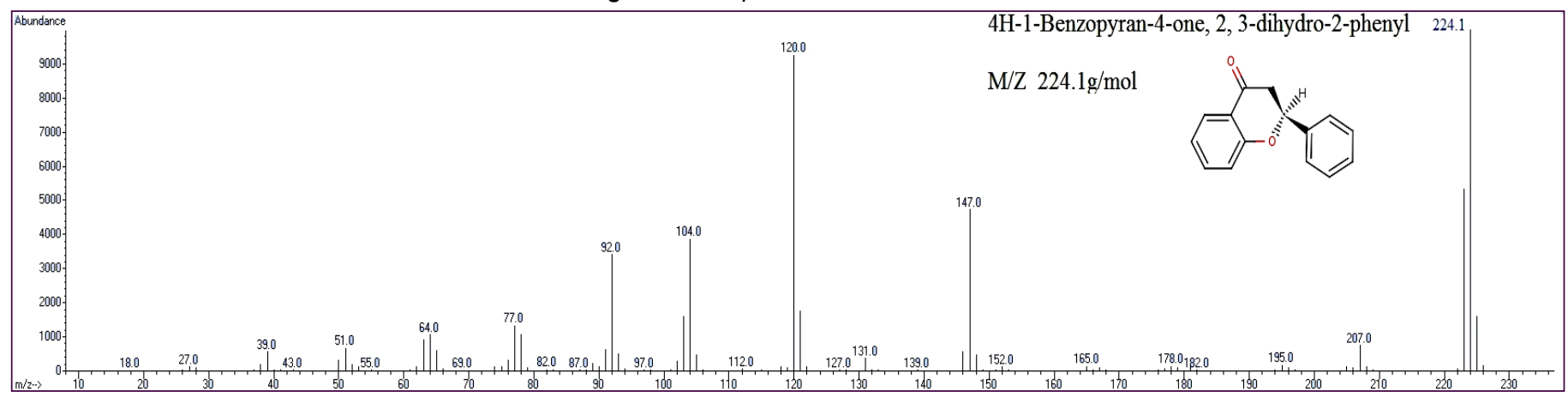

Fig. 4- Mass spectrum of 4-Flavanone

Many studies have been carried out on the second volatile compound 4-flavanone (4H-1-Benzopyran-4-one, 2, 3-dihydro-2phenyl). Flavanones are considered an imperative group of naturally occurring secondary metabolites; they are important intermediates for the synthesis of biologically active flavones and isoflavones. Flavonoids and flavanones have attracted considerable attention for their interesting biological activities like antimicrobial [17,18], antibacterial [19], antifungal [20], antiviral [21], antihypertensive [22], antioxidants [22], anti-inflammatory [22], anti-lung cancer [23] and antiviral [21] effects. Kamboj, et al. [24] evaluated the antimicrobial activity of some flavanone compounds against some pathogenic bacteria and fungi and concluded that all tested flavanones exhibited antibacterial and antifungal activity against some G+ve bacteria Staphylococcus aureus and Bacillus subtilis. However, all tested compounds were ineffective against some G-ve bacteria Escherichia coli and Pseudomonas aeruginosa. In addition, all tested flavanones showed antifungal activity against Aspergillus niger and $A$. flavus isolated from human patients of $55 \%$ for both fungi [24]. Vatkar, et al. [18] screened the antimicrobial activity of Flavanone against some bacteria and fungi and found that all tested compounds showed effective antibacterial activity against $E$. coli and $P$. aeruginosa and antifungal activity against $A$. niger and $A$. flavus. Cao, et al. [25] isolated two flavanone compounds: (2R, 3R)8-lavandulyl-2'-methoxy-5, 7, 4'-trihydroxyflavanonol and 8lavandulyl-5, 7, 4'-trihydroxyflavonol from the dry roots of Sophara flavescens and studied their antimicrobial activity and concluded that both compounds exhibited significant antibacterial activity against Staphylococcus aureus and Bacillus subtilis equally as chloramphenicol which was used as positive control. Cushnie and Lamb [26] reviewed that some flavonoids compounds showed antiviral activity against human immunodeficiency virus (HIV).

The mechanism of antimicrobial activity of identified 4-flavanone compound could be demonstrated by the presence of $(-\mathrm{OH})$ group which possess highly antimicrobial activity. Whereas, the incorpora- 
tion of $\left(-\mathrm{CH}_{3}\right)$ and $\left(-\mathrm{OCH}_{3}\right)$ groups cause the diminution in antimicrobial activity.

\section{Bioactivity of VOCs Standards of d Limonene and 4-Flavanone}

As summarized in [Table-2], both studied standards were able to inhibit the growth of fungal mycelium individually and in synergic combination against the same target tested organisms F.oxy and R.sol. The obtained results verified our hypothesis that VOCs which produced by Bga strain ICMP11096 and have been identified as d limonene and 4-flavanone could be responsible for the antifungal activity against the target tested organisms. Further studies are important to determine exactly the Minimum Inhibitory Concentration (MIC) of both substances which able to inhibit completely the fungal growth.

Table 2- Fungitoxicity percentage of standards d Limonene and 4-

\begin{tabular}{lcc|}
\multicolumn{3}{c}{ Flavanone } \\
\hline Standards & \multicolumn{2}{c|}{ Fungitoxicity percentage } \\
& F. oxysporum & R. solani \\
\hline d Limonene & 31.7 & 57.6 \\
4-Flavanone & 44.7 & 49.4 \\
Synergic effect & 60 & 69.4 \\
\hline
\end{tabular}

\section{Conclusion}

Studied strains of Bga were able to antagonize important plant pathogenic fungi such as F.oxy and R.sol by producing some volatile bioactive secondary metabolites. The most bioactive Bga strain ICMP11096 produced two bioactive compounds. The first one was classified as liquid hydrocarbon of cyclic terpene and considered one of the more frequent $d$ isomer of limonene whereas the second compound was classified as 4-flavanone. The obtained results stated that the studied bacterial Burkholderia strains could be used effectively as biological control agents against two tested phytopathogenic fungi due to their production of bioactive volatile compounds. Further studies are necessary for comparing the bioactivity of naturally isolated volatile compounds with the commercial synthetic pesticides, verify the efficacy of isolated VOCs against other pathogenic fungi and find out the mode of use of these natural substances in controlling plant pathogens practically.

\section{Acknowledgments}

We are grateful to Prof. Gian Luigi Rana for critical revision of the manuscript. Thanks for the technical assistance from C.T. Michele Palumbo and Shimaa Sakr.

\section{Conflict of Interest}

The authors declare no conflict of interest.

\section{List of Abbreviations}

Bga : Burkholderia gladioli pv. agaricicola

CFU : Colony Form Unit

ICMP : International Collection of Microorganisms from Plants

PDA : Potato Dextrose Agar

F.oxy : Fusarium oxysporum

R.sol: Rhizoctonia solani

Ua.ml-1 : Unit active of millilitre

VOCs : Volatile Organic Compounds

GC-MS : Gas Chromatography-Mass Spectrometry

SPME : Solid Phase Micro Extraction

\section{References}

[1] Duffy B.K. and Defago G. (1999) Appl. Environ. Microbiol., 65, 2429-2438.

[2] Liu X., Bimerew M., Ma Y., Muller H., Ovardis M., Eberl L., Berg G., Chernin L. (2007) FEMS Microbiol. Lett., 270, 299-305.

[3] Alstrom S. (2001) J. Phytopathol., 149, 57-64.

[4] Wheatley R.E. (2002) Ant. Lee., 81, 357-364.

[5] Schmidt S., Blom J.F., Pernthaler J., Berg G., Baldwin A., Mahenthiralingam E. and Eberl L. (2009) Environ. Microbiol., 11, 1422-1437.

[6] Schöller C.E., Gürtler H., Petersen R., Molin S., Wilkins K. (2002) J. Agricul. Food Chem., 50, 2615-2621.

[7] Piechulla B., Pott M.B. (2003) Planta, 217(5), 687-689.

[8] Dickschat J.S., Martens R., Brinkho V.T., Simon M., Schulz S. (2005) Chem. Biodivers., 2, 837-865.

[9] Compant S., Nowak J., Coenye T., Clement C., Ait Barka E. (2008) FEMS Microbiol. Rev., 32, 607-626.

[10]Andolfi A., Cimmino A., Lo Cantore P., lacobellis N.S., Evidente A. (2008) Perspect. Med. Chem., 2, 81-112.

[11]Elshafie H.S., Camele I., Racioppi R., Scrano L., lacobellis N.S. and Bufo S.A. (2012) Int. J. Mol. Sci., 13, 16291-16302.

[12]King E.O., Ward M.K., Raney D.E. (1954) J. Lab. Clin. Med., 44, 301-307.

[13]Wan M., Li G., Zhang J., Jiang D. and Huang H. (2008). Biol. Control, 46(3), 552-559.

[14]Zygadlo J.A., Guzman C.A., Grosso N.R. (1994) Oil Res., 6, 617-621.

[15]Ayoola G.A., Johnson O.O., Adelowotan T., Aibinu I.E., Adenipekun E., Adepoju-Bello A.A., Coker H.A.B., Odugbemi T.O. (2008) Afr. J. Biotechnol., 7, 2227-2231.

[16]Hossain M.A, Ismail Z., Rahman A., Kang S.C. (2008) Ind. Crop Prod., 27, 328-334.

[17]Ghani S.B., Weaver L., Zidan H.Z., Ali H.M., Keevil C.W., Brown R.C. (2008) Bioorg. Med. Chem., 18, 518-522.

[18]Vatkar B.S., Pratapwar A.S., Tapas A. R., Butle S.R. and Tiwari B. (2010) Int. J. Chem. Tech. Res., 2(1), 504-508.

[19]Mughal E.U., Ayaz M., Hussain Z., Hasan A., Sadiq A., Riaz M., Malik A., Hussain S., Choudhary M.I. (2006) Bioorg. Med. Chem., 14, 4704-4714.

[20]Dandia A., Singh R., Khaturia S. (2006) Bioorg. Med. Chem., 14, 1303-1308.

[21]Pandey V.K., Singh V.K., Tandon M., Joshi M.N., Bajpai S.K. (2004) Ind. J. Chem., 43(B), 1770-1773.

[22]Tapas A., Sakarkar D., Kakde R. (2008) Res. J. Pharm. and Tech., 1(3), 132-143.

[23]Hammam A.G., Abd El-Salam O.I., Mohamed A., Abdel Hafez N. (2005) Ind. J. Chem., 44(B), 1887-1893.

[24]Kamboj R.C., Sharma G., Kumar D. (2011) Int. J. Chem. Tech., 3(2), 901-910.

[25]Cao M.A., Sun X.B., Zhao P.H., Yuan C.S. (2006) Chinese Chem. Lett., 17(8), 1048-1050.

[26]Cushnie T.T., Lamb A.G. (2005) Int. J. Antimicrob. Agents, 26, 343-356. 